\section{Son of Dimebon}

\section{By Chris Cain, Staff Writer}

When Medivation Inc.'s Dimebon latrepirdine failed in a Phase III trial in Alzheimer's disease, it came as no surprise to skeptics of the compound who had long doubted the generic antihistamine, for which a mechanism of action could not be identified in AD. But now, in a quest for small molecule neurogenesis stimulators, researchers at The University of Texas Southwestern Medical Center at Dallas have identified a compound that has a structure and neuroprotective function surprisingly similar to those of Dimebon. ${ }^{1}$

The new molecule, $\mathrm{P} 7 \mathrm{C} 3$, is more potent than Dimebon and could be a starting point for the design of stronger molecules. The research also begins to offer new clues on how these molecules may work.

The UT Southwestern group identified P7C3 by screening drug-like compounds in wild-type mice for their ability to increase hippocampal neurogenesis. Out of 1,000 compounds, P7C3 was the most potent neurogenesis-stimulating molecule in wild-type mice, and it was also able to restore neurogenesis in mice with a genetic mutation that severely reduced hippocampal neurogenesis.

In aged rats injected with P7C3, cognitive abilities in a water maze test were significantly better than those of rats given vehicle control $(p<0.01)$.

"Many studies have shown that exercise, social or environmental enrichment and other activities generally thought of as good for your brain stimulate hippocampal neurogenesis," said Andrew Pieper, an assistant professor of psychiatry who co-led the team along with Steve McKnight, professor and chair of the Department of Biochemistry. "We wanted to find a chemical that would have that property."

Their group thinks P7C3 fits the bill, but a detailed investigation of the chemical, described in Cell, provided some unexpected results.

The first surprise came when the researchers started to tease out P7C3's mechanism. Compared with vehicle-treated control rats, P7C3-treated animals had lower levels of neuronal apoptosis in the hippocampus, suggesting the compound had a neuroprotective effect.

"We were fully expecting this compound to act by increasing the division of neural precursor cells," said McKnight. "But we were surprised to find that it does not stimulate division, but instead prevents the death of maturing neural precursor cells."

This neuroprotective effect leads to greater neurogenesis as more pre- cursor cells eventually develop into mature hippocampal neurons. The majority of these developing cells would not normally survive the maturation process. However, mice receiving oral P7C3 had a 500\% increase in the abundance of newly matured neurons compared with mice receiving a vehicle control.

A major pathway leading to apoptosis is the disruption of mitochondrial integrity. Thus, the UT Southwestern team looked at whether P7C3 had any effects on that organelle. Using cell culture assays, they found that $\mathrm{P7C} 3$ preserved mitochondrial integrity in the presence of a calcium ionophore that disrupts membrane potential and leads to the destruction of mitochondria.

The second surprise came when the researchers looked at other compounds known to protect mitochondria and found that P7C3 had structural similarity to Dimebon, which also was able to stimulate neurogenesis in mice.

"What is most remarkable about this paper is that two completely independent lines of research have identified a virtually identical chemical with neuroprotective and neurogenic properties," said Medivation president and CEO David Hung. "Dimebon is a carboline, while $\mathrm{P} 7 \mathrm{C} 3$ is a carbozole, and these two molecules differ primarily by an aromatic residue at one position. We believe Dimebon is acting through the same mechanism- by protecting mitochondrial integrity."

In vitro, $\mathrm{P7C} 3$ protected mitochondrial integrity at a concentration 100 -fold lower than that for Dimebon. In mice, P7C3 was 10-fold more potent than Dimebon in stimulating hippocampal neurogenesis.

"This molecule could potentially be developed into a more powerful Dimebon," said McKnight.

Earlier this year, Dimebon missed the primary and secondary endpoints in a Phase III trial in patients with mild to moderate AD. ${ }^{2}$ Neither Medivation nor partner Pfizer Inc. have discussed reasons for the failure, which could range anywhere from trial design to potency issues. A Phase III trial is ongoing to investigate Dimebon's therapeutic potential in patients with Huntington's disease (HD).

\section{Mystery mechanism}

Despite hints that mitochondria may mediate the neuroprotective effects of both Dimebon and P7C3, the molecular targets of the compounds are still unknown. Although one demonstrated function of Dimebon is as an antihistamine, proneurogenic derivatives of $\mathrm{P} 7 \mathrm{C} 3$ have been developed that retain no activity to known histamine receptors, suggesting these molecules have another cellular target.

"We are killing ourselves to find the mechanism-we really don't know what it is," said McKnight. "We hope to be the ones to find it, but now that this paper is out other groups may get there first."

In parallel with its efforts to discover the mechanism, the UT Southwestern group is investigating the effect of $\mathrm{P} 7 \mathrm{C} 3$ on existing adult 


\section{ANALYSIS}

\section{TARGETS \& MECHANISMS}

neurons in the hippocampus. Although the chemical protects neural precursor cells, it is unclear if the therapeutic will result in similar protection for mature neurons, which are the ones that get damaged and destroyed in $\mathrm{AD}$ and other neurodegenerative diseases.

"Experiments testing this compound in mouse models are ongoing in our lab" and include models of spinocerebellar ataxia, amyotrophic lateral sclerosis (ALS) and HD, said McKnight.

UT Southwestern has filed for patents covering P7C3's use in neuroprotection. Hung would not discuss if there are any potential conflicts with Medivation's IP covering Dimebon.

Cain, C. SciBX 3(29); doi:10.1038/scibx.2010.883

Published online July 29, 2010

\section{REFERENCES}

1. Pieper, A.A. et al. Cell; published online July 8, 2010; doi:10.1016/j.cell.2010.06.018

Contact: Steve L. McKnight, The University of Texas Southwestern Medical Center at Dallas, Dallas, Texas

e-mail: steven.mcknight@utsouthwestern.edu

Contact: Andrew A. Pieper, same affiliation as above

e-mail: andrew.pieper@utsouthwestern.edu

2. Lawrence, S. BioCentury 18(11), A23; March 8, 2010

COMPANIES AND INSTITUTIONS MENTIONED

Medivation Inc. (NASDAQ:MDVN), San Francisco, Calif.

Pfizer Inc. (NYSE:PFE), New York, N.Y.

The University of Texas Southwestern Medical Center at Dallas, Dallas, Texas 